\title{
Factors Affecting the Intensive Care Stay of Patients with Spinal Neural Tube Defects
}

\author{
Durmus Oguz KARAKOYUN ${ }^{1}$, Yucel DUZENLI² \\ ${ }^{1}$ Ordu University School of Medicine, Department of Neurosurgery, Ordu, Turkey \\ ${ }^{2}$ Dr. Ersin Arslan Training and Research Hospital, Department of Neurosurgery, Gaziantep, Turkey
}

Corresponding author: Durmuş Oğuz KARAKOYUN droguzk@gmail.com

\section{ABSTRACT}

\begin{abstract}
AIM: To evaluate the duration of hospitalization and the factors that increase this duration in cases treated in the neonatal intensive care unit with the diagnosis of a spinal neural tube defect (NTD).

MATERIAL and METHODS: The demographic characteristics, NTD type and level, ventriculoperitoneal (V-P) shunt needs, accompanying spinal deformity, antibiotherapy applied during treatment, and intensive care stay periods of 73 patients treated in our clinic between July 2017 and 2020 were retrospectively evaluated.
\end{abstract}

RESULTS: The intensive care stay of NTD cases was 7-109 (mean=23) days. Fifty-one cases (69.9\%) had myeloschisis, and 22 cases $(30.1 \%)$ had myelomeningocele (MMC) sac. A V-P shunt was applied to 24 cases $(32.9 \%)$ during hospitalization, and additional antibiotherapy was given to $32(43.8 \%)$ cases.

CONCLUSION: In myeloschisis cases compared with MMC marsupial cases, incidences of ventricular dilatation, kyphotic/scoliotic spine pathology, V-P shunt requirement, and longer hospital stay were observed. No difference in the duration of hospitalization was found in patients who underwent defect repair between the first day and $48 \mathrm{~h}$ after birth. However, the length of stay in hospital increased in patients operated on after $48 \mathrm{~h}$. The period was longer in cases operated after seven days postnatally. Therefore, by performing NTD surgical treatment within the first 48 hours, the need for additional antibiotherapy and hospital stay can be shortened.

KEYWORDS: Myelomeningocele, Intensive care unit stay, Ventriculoperitoneal shunt, Children

\section{INTRODUCTION}

$\mathrm{N}$ eural tube defect (NTD) is a congenital central nervous system anomaly that causes mortality and morbidity. NTD is a congenital malformation in which the spinal cord is divided (bifid) as a result of incomplete closure of the embryonic neural tube due to its success in primary or secondary neuralization at intrauterine $3-4$ weeks (9). The most common clinical variants of NTDs are spina bifida occulta, spina bifida cystica (meningocele, myelomeningocele), myeloschisis, and anencephaly (3). In myelomeningocele (MMC), there is a defect in the junction of the lateral edges of the neural placode in the midline, and an opening is observed in the dorsal of the spinal cord due to this defect. It can occur anywhere in the spine, but is more common in the lumbosacral region (19).
Although the etiology of NTD is not fully understood, it has been shown to be associated with genetic reasons, geographical differences, low socio-economic status, and folic acid deficiency (5). Damage to the spinal cord and peripheral nerves is evident at birth. In the lower extremities, it causes a neurological dysfunction associated with the spinal cord level of the lesion (23).

In these cases, bowel and bladder dysfunctions are observed in addition to paralysis, loss of sensation, and muscle atrophy in the lower extremities. Orthopedic disorders (e.g., clubfoot, hip dislocation, contractures, kyphosis, and scoliosis) and other anomalies of the nervous system (e.g., Chiari type 2, hydrocephalus) also frequently occur (31). Although it has been reported that minimal neurological deficits and good 
clinical results can be obtained by applying maternal-fetal surgical procedures for the treatment of MMC cases, this treatment can be applied in a limited number of centers due to the need for appropriate materials, resources, and personnel (8). Nevertheless, the method commonly used for the repair of the sac is the postnatal procedure (28). This surgical treatment aims to close the exposed spinal cord and nerve roots without cerebrospinal fluid (CSF) leakage. Therefore, central nervous system infections due to CSF leakage are prevented (19).

This study evaluates the types of spinal NTDs operated in our hospital, the follow-up and treatment times in the intensive care unit, and the factors affecting this duration.

\section{MATERIAL and METHODS}

Ethics committee approval for our study numbered 161 was obtained from Ordu University on August 20, 2020 (Approval No:161).

Seventy-three cases who were hospitalized in the neonatal intensive care clinic with diagnosis of NTD and operated by a single surgeon in the Neurosurgery Clinic between 2017 and 2020 at the Gaziantep Dr. Ersin Arslan Training and Research Hospital were retrospectively screened. The cases were evaluated in terms of gender, birth weight, NTD localization and type, time of operation, presence of ventricular dilatation, time of ventriculoperitoneal (V-P) shunt application, type of antibiotherapy applied during treatment, and duration of hospitalization. Postnatal cranial and spinal magnetic resonance imaging (MRI) was performed on all cases. With MRI examination, the cases with hydrocephalus, localization of the MMC lesion, and congenital central nervous system anomalies were evaluated (Figure 1A-D). In addition, computed tomography (CT) examination was performed during the follow-up of the patients' hydrocephalus.

The cases were grouped in terms of the time they underwent surgery. Accordingly, those who were operated within the first 24 hours after birth were classified as Group A, those who were operated within 24-48 hours as Group B, those who were operated within 3-7 days as Group C, and those who were operated after 7 days as Group D.

The cases were also grouped by NTD type. The V-P shunt requirements for patients with myeloschisis and myelomeningocele cysts were evaluated in terms of the rate of accompanying kyphotic/scoliotic deformity, additional antibiotherapy needs, and length of stay.

\section{Surgical Technique}

All patients were operated under general anesthesia in the prone position with neuromonitoring. Subcutaneous tissue adjacent to the defect was detached. The dura defect on the neural plate was primarily repaired (Figure 2A, B). In cases deemed necessary, it was closed with a synthetic dural graft. After the dura repair, the Valsalva maneuver was performed, and no CSF leak was observed. Following hemostasis, the subcutaneous/skin defect was closed (Figure 3A, B).

\section{Clinical Observation}

Cefotaxime and amikacin treatment was started as prophylactic after the cases were admitted to the intensive care unit. Following the sending of blood, urine, wound, and tracheal aspiration cultures from the patients with high fever and high CRP in their follow-up, vancomycin and meronem treatments were started. According to the culture results, antibiotics were changed or continued. Daily head circumference followup, MRI, or CT examination was performed according to the hydrocephalus clinic of the cases. A V-P shunt was applied to the patients diagnosed with hydrocephalus in the same session or in a different session according to their clinical follow-up.

\section{Statistical Analysis}

SPSS statistical software (SPSS 11.5, SPSS Science, Chicago, IL, USA) program was used for statistical analysis. For data analysis, the Mann-Whitney $\mathrm{U}$ test, Kruskal-Wallis $\mathrm{H}$ test, and chi-square test were used.

\section{RESULTS}

Among the cases, 40 (54.8\%) were female and $33(45.2 \%)$ were male. Fifty-four patients (74\%) were refugees of Syrian origin, and 19 (26\%) were citizens of the Republic of Turkey. Birth weights were between $2,000 \mathrm{gm}$ and 5,030 gm (mean $=3,177 \mathrm{gm}$ ). The admission period of the patients to the hospital ranged from just after delivery to the postnatal $27^{\text {th }}$ day. Nineteen $(26 \%)$ refugee cases, who were referred to our clinic from abroad, were admitted to the hospital on the

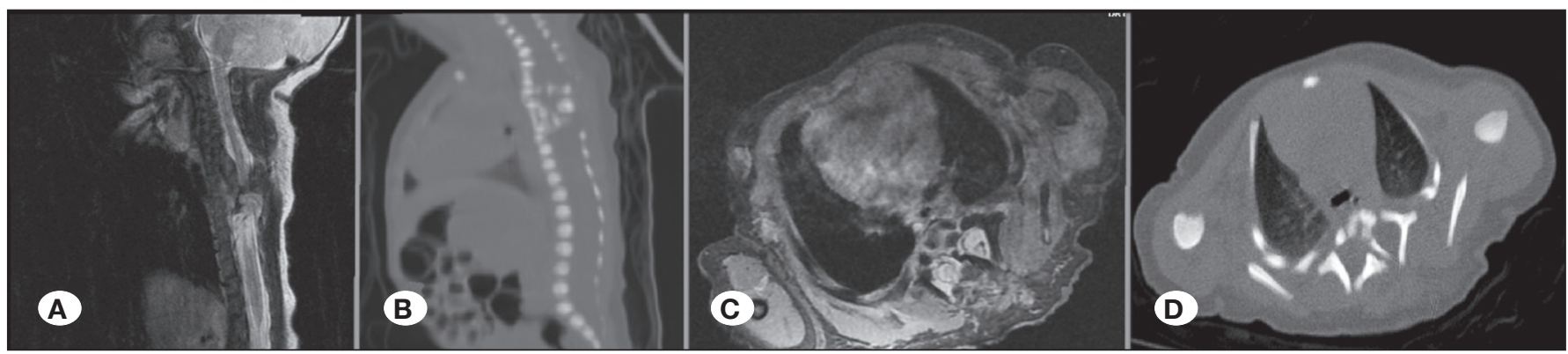

Figure 1: A) MMC seen in thoracic region on T2 sequence sagittal MRI. B) The bone deformity seen in the spinal canal in the sagittal CT examination of the lesion, $\mathbf{C}$ ) formation of two separate vertebral canals in the thoracic region in axial MRI examination of the case, and D) image of two separate spinal canals in thoracic axial CT examination. 


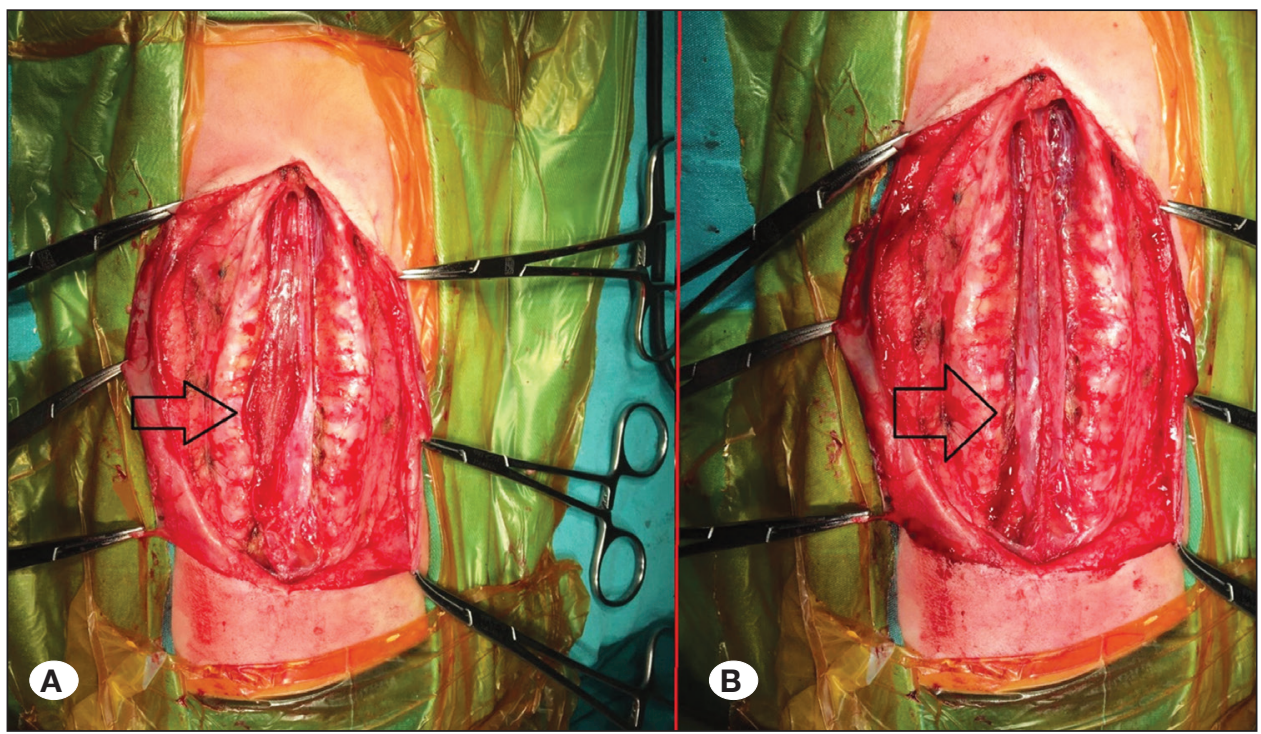

Figure 2: A) The peroperative view of the preparation of the subcutaneous tissue made for the repair of the neural plaque and skin defect is observed. B) Primary suturation of the dura and repair of the neural sac.

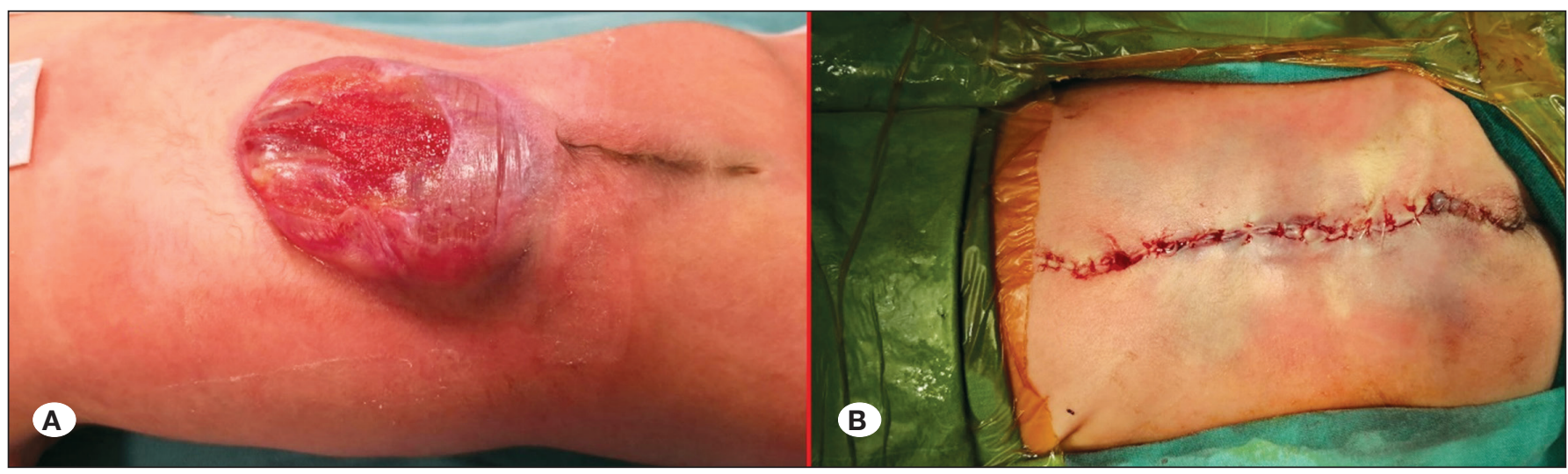

Figure 3: A) MMC appears localized in the thoracolumbar region. B) Primary skin closure.

$3^{\text {rd }}-27^{\text {th }}$ day postnatal (mean=8.4). The cases were operated between the first postnatal day and their $29^{\text {th }}$ day (mean=4.4).

The patients were hospitalized in the intensive care unit for 7-109 days (mean=23). When the intensive care hospitalization periods were examined according to the groups, the longest hospitalization period was in the patients who were operated on after the seventh postnatal day. When the hospitalization periods of the groups were compared, no significant difference was found between Groups A and B, but the difference between Groups B and C and between Groups C and D was significant. The distribution of cases and the hospitalization periods in the groups are given in Table I, and the statistical comparison is presented in Table II.

V-P shunt operation was applied to 24 cases (32.9\%) but not to 49 cases $(67.1 \%)$. Forty-one $(56.2 \%)$ cases were given prophylactic antibiotherapy only during their hospitalization, and 32 (43.8\%) patients required additional antibiotherapy during their hospitalization. The rate of applying V-P shunt and additional antibiotherapy was higher in patients who were operated on after the seventh day. However, this high rate was not statistically significant due to the small number of patients in group $\mathrm{D}$ (Table III).

In the distribution of the cases by NTD type, 51 (69.9\%) had myeloschisis and 22 (30.1\%) had MMC sac. The incidences of kyphotic or scoliotic spine deformation and ventricular dilatation at birth were higher in cases with myeloschisis than in those with MMC marsupials. In cases with myeloschisis, the V-P shunt application rate, additional antibiotic requirement, and long hospital stay were higher in the clinical follow-up. These values were statistically significant (Tables IV).

V-P shunt operation was performed between the postnatal $3^{\text {rd }}$ $60^{\text {th }}$ day (mean=21.6). It was performed in the same session, with defect repair in only one case. Shunt insertion was conducted in different sessions in 23 cases (95.8\%). None of our patients required shunt revision during the hospitalization period.

The MMC sac was located in the lumbosacral region in 20 cases $(90.9 \%)$ and in the thoracal region in two cases $(9.1 \%)$. The myeloschisis cases were distributed according to their 
Table I: Case Distribution of the Groups and Length of Stay According to the Duration of the Operation

\begin{tabular}{lcccc}
\hline & Group A & Group B & Group C & Group D \\
\hline $\mathrm{n},(\%)$ & $16(21.9)$ & $15(20.5)$ & $33(45.2)$ & $9(12.3)$ \\
\hline Hospitalization periods & & & & \\
$\quad$ Min/max & $8-25$ & $8-55$ & $7-55$ & $15-109$ \\
Mean & 17.4 & 17.2 & 23.6 & 40.6 \\
SD & 5.59 & 12.27 & 12.23 & 28.59 \\
\hline
\end{tabular}

Table II: Statistical Comparison of the Groups According to the Length of Hospital Stay

\begin{tabular}{cccc}
\hline Group 1-2 & Group 1-4 & Group 2-3 & Group 3-4 \\
\hline$p>0.05$ & $p<0.006$ & $p<0.042$ & $p<0.041$ \\
\hline
\end{tabular}

Table III: Additional Antibiotherapy and V-P Shunt Application Rates of the Cases According to the Operation Time

\begin{tabular}{|c|c|c|c|c|c|}
\hline & $\begin{array}{c}\text { Number of cases, } \\
(\%)\end{array}$ & Group A & Group B & Group C & Group D \\
\hline \multicolumn{6}{|l|}{ V-P shunt } \\
\hline placed & 24 (32.9) & $6(37.5)$ & 2 (13.3) & $11(33.3)$ & $5(55.6)$ \\
\hline not placed & $49(67.1)$ & $10(62.5)$ & $13(86.7)$ & $22(66.7)$ & $4(44.4)$ \\
\hline \multicolumn{6}{|l|}{ Use of antibiotics } \\
\hline additional antibiotics & $32(43.8)$ & 5 (31.3) & $6(40)$ & $14(42.4)$ & $7(77.8)$ \\
\hline prophylactic antibiotics & 41 (56.2) & $11(68.8)$ & $9(60)$ & $19(57.6)$ & $2(22.2)$ \\
\hline
\end{tabular}

Table IV: The Statistical Evaluation of the Effect of Ventricular Dilatation, V-P Shunt Application Rate, Accompanying Kyphotic / Scoliotic Deformity and Additional Antibiotherapy and Length of Stay According to NTD Types

\begin{tabular}{|c|c|c|c|c|}
\hline & n (\%) & MMC sac & Myeloschisis & $\mathbf{p}$ \\
\hline Number of Cases & $73(100)$ & $22(30.1)$ & $51(69.9)$ & \\
\hline Ventricular dilatation & $41(56.2)$ & $3(7.3)$ & $38(92.7)$ & $<0.001$ \\
\hline V-P shunt application rate & $24(32.9)$ & $1(4.2)$ & $23(95.8)$ & $<0.001$ \\
\hline Kyphotic- scoliotic deformity & 17 (23.3) & $-(0)$ & $17(100)$ & $<0.002$ \\
\hline The need for additional antibiotherapy & $32(43.8)$ & $5(15.6)$ & $27(84.4)$ & $<0.021$ \\
\hline \multicolumn{5}{|l|}{ Hospitalization periods } \\
\hline Min $/ \max$ & $7-109$ & $7-41$ & $8-109$ & \\
\hline Mean & 23 & 16.4 & 25.8 & $<0.002$ \\
\hline SD & & 9.81 & 16.91 & \\
\hline
\end{tabular}

localization in the spinal canal as follows: thoracolumbar in 35 cases (68.6\%), lumbar in 5 cases $(9.8 \%)$, lumbosacral in 5 cases $(9.8 \%)$, thoracic in 5 cases $(9.8 \%)$, and cervical region in 1 case $(1.9 \%)$.

The number of cases with low birth weight ( LBW) $(<2500 \mathrm{gr}$ ) was $10(13.7 \%)$, and 9 of these cases (90\%) were refugees of Syrian origin. The treatment period of these cases was 10-55 days (mean=26.7). The treatment period of cases without LBW was 7-109 days (mean=22.4). Additional antibiotherapy was required in five (50\%) of these cases, and a V-P shunt was required in four (40\%) of them. Two LBW cases $(2.7 \%)$ died in the postoperative period.
The referral of 19 refugee cases $(24.7 \%)$ from Syria to our hospital was within 3-27 days (mean=8.4). The length of stay in the intensive care unit of these patients was 8-109 days (mean=32.7). In 13 of these cases $(68.4 \%)$, antibiotherapy was given in addition to prophylactic antibiotic treatment. In nine of these cases (47.4\%), shunt application was required during the intensive care follow-up.

\section{DISCUSSION}

NTD incidence per 1,000 live births is $0.8-1.0$ worldwide (39), $0.5-1.0$ in the United States (34), 0.91 in European countries 
(18), 0.62-13.8 in Arabic countries (14), and 5.6 in Turkey (37). The risk of anencephaly and spina bifida is known to increase with the use of insufficient folate or its synthetic form, folic acid, before and during pregnancy (23). According to case control studies and randomized clinical studies, if pregnant women do not take folic acid supplements or multivitamin supplements containing folic acid, they are 2-8 times more likely to be at risk (39). NTD affecting the lumbar spine is commonly seen in societies with a low socio-economic status (19). As the city where our hospital is located is found on the Syrian border, most of our cases are refugees residing in our country due to the Syrian civil war or those who were referred to our hospital because they could not obtain adequate healthcare despite living in their country. Owing to the current situation in this region, the low socio-economic level increases the number of cases and makes obtaining health services difficult. Thus, 74\% of our cases consisted of Syrian origin refugees. In addition, 19 of these cases were born in Syria, but were referred to our hospital for surgical treatment due to the lack of equipment there. It was observed that $68 \%$ of these cases received additional antibiotic treatment and $47 \%$ needed a V-P shunt and the length of hospital stay was observed due to these reasons. In these regions, planning should be made for the detection of NTD cases by increasing pregnancy follow-ups and for the realization of labor in centers where postpartum treatment can be performed.

MMC is most frequently localized in the lumbar region (69\%) (15). Eseoglu et al. reported that MMC distribution was $76.5 \%$ in the lumbar region, $10.9 \%$ in the thoracolumbar region, $3.1 \%$ in the thoracic region, and $1.5 \%$ in the cervical region (12). In our study, the lesion was mostly located in the lumbosacral region (90.9\%) in patients with MMC sac and in the thoracolumbar region (68.6\%) in patients with myelochisia. Contrary to the literature, cases with myeloschisis (69.9\%) were more common than cases with MMC sac (30.1\%). This may be due to the regular follow-up during the gestational period compared with the past, the easier detection of the MMC sac in the intrauterine period compared with myeloschisis, and the termination of such pregnancies in the early period. Cases with lesions with a smaller MMC diameter have a shorter hospital stay, less neurological complications are seen in the early period, and an increase in the diameter of the sac increases the duration of antibiotherapy and adversely affects the prognosis (12). In our study, patients with myeloschisis were hospitalized longer than MMC cases, the need for V-P shunts increased, kyphotic/scoliotic spine defects were frequent, and additional antibiotherapy was required.

The timing of the postnatal surgical repair of NTDs is a controversial issue in the literature. Arslan et al. reported that delay in the repair of NTD caused an increase in the general infection rate (1). John et al. found that the rate of wound infection and meningitis was lower in patients who underwent surgical repair within 48 hours $(2,16)$. Charney et al. found no significant difference in ventriculitis between those who were closed within the first 48 hours and those who were closed 3-7 days later (7). Pinto et al. reported no difference in wound infection between patients who were operated immediately after birth and those who were operated on 3.9 days later
(29). In our study, the use of additional antibiotics was higher in patients who were operated after seven days, but the difference was not statistically significant. The rate of additional antibiotherapy use was higher in cases with myeloschisis than in cases with MMM sac, and the difference was statistically significant. No significant difference was found in terms of hospital stay between patients who were operated in the first 24 hours and those who were operated within 48 hours. However, the hospitalization period of the cases operated in 3-7 days was longer than the cases operated in the first 48 hours. Those who were operated after seven days stayed in the hospital for a longer period than the patients who were operated within 3-7 days. Wound infection or ventriculitis that may develop due to colonization on NTD due to delay in surgical treatment may require additional antibiotics and prolong the stay. In addition, since hydrocephalus may develop in the patient after central nervous system infection, follow-up may have extended the length of stay in terms of the need for V-P shunt. In our study, it was observed that patients who were operated after the $2^{\text {nd }}$ day had longer treatment times and if the expected time for defect repair was prolonged, the duration of hospital stay was also prolonged. Therefore, if the patients are operated within the first 48 hours, the need for additional antibiotics can be reduced and the length of hospital stay can be shortened.

Ersahin and Yurtseven reported that the defects seen in their study were mostly small and could be closed by bringing the neural plate close to the midline without tension, but that the defects could be large in $25 \%$ of cases (11). According to Ramasastry and Cohen, if the diameter of the defect is greater than $5 \mathrm{~cm}$, the defect can be repaired with reconstruction flaps (30). Musculocutaneous flaps can be used to close excessively enlarged MMC defects (25). Various reconstruction methods have been described in the literature $(7,10,17,22,24,33,38)$. Regardless of the size of the lesion in our cases, sufficient subcutaneous tissue was detached, duroplasty was performed, and the skin was closed by approximation to the midline. None of our patients required wound site revision.

Large-sized MMCs are usually found in the thoracolumbar and lumbar regions. Nejat et al. reported that these lesions were mostly associated with symptomatic hydrocephalus and severe neurological deficits, and that simultaneous V-P shunting with defect repair would increase the duration and cost of surgery while reducing the risk of CSF leak (26). As only $2 \%-25 \%$ of MMC patients have obvious hydrocephalus $(1,20)$, simultaneous shunt operation for MMC repair is doubtful, and it can increase the risk of shunt infection and failure in simultaneous shunt application $(35,36)$. No difference was found in terms of the development of shunt infection between V-P shunt application performed simultaneously with MMC repair and its application in the first and second weeks (13). Chakraborty et al. found that moderate ventriculomegaly could occur after MMC repair, which is a slight progression, and that unnecessary shunts should be avoided and close follow-up should be performed in asymptomatic patients instead of wearing shunts (6). Similarly, Oktem et al. confirmed that shunting in the same session as MMC sac repair is not acceptable and recommended shunting in a separate session 
in appropriate cases if there are no signs of infection (27). Sankhla and Khan reported that mild-to-moderate ventricular dilatation could be seen after MMC repair, and that increases in ventricle size could be treated without a shunt. Shunt application was recommended for severe hydrocephalus cases in the high intracranial pressure clinic, and shunt was applied in $56 \%$ of the cases in their study (32). Mapstone et al. reported that cases not requiring shunt insertion reached higher IQ levels than cases that required shunt insertion (21). Our rate of applying V-P shunt to our cases was $32.9 \%$, and all these cases had myeloschisis. A shunt decision was made in all our cases after clinical and radiological follow-up, except for one patient with the same session. This situation prolonged our intensive care follow-up periods. In addition, there was no complication due to shunt application or a need for shunt revision in our cases.

MMC cases require constant surveillance of neurological, urological, and musculoskeletal systems after the neonatal period. Routine measurements for head circumference should be taken, followed up for shunt dysfunction and infection, and monitored for neurological complications, such as tethered cord and seizure (23). Patients should be monitored for urological complications (urinary retention, ureteral reflux) that could occur due to abnormal neurogenic bladder dysfunction. Personalized continence programs should be established in terms of renal failure as a result of recurrent urinary tract infections (4).

Our study has several limitations. It was performed on a relatively limited number of cases, and its retrospective nature could diminish its scientific value. The lack of prenatal followups and information about when and how the birth was taken for all cases from the Syrian region and the lack of regular post-discharge check-ups also limited our study. Therefore, prospective, large-scale, multi-center clinical trials are needed to further validate our results.

\section{CONCLUSION}

In myeloschisis cases compared with MMC marsupial cases, incidences of ventricular dilatation, kyphotic/scoliotic spine pathology, V-P shunt requirement, and longer hospital stay were observed. No difference in the duration of hospitalization was found in patients who underwent defect repair between the first day and 48 hours after birth. However, the length of stay in hospital increased in patients operated on after 48 hours. The period was longer in cases operated after seven days postnatally. Therefore, by performing NTD surgical treatment within the first 48 hours, the need for additional antibiotherapy and hospital stay can be shortened.

\section{REFERENCES}

1. Arslan M, Eseoglu M, Gudu BO, Demir I, Kozan A, Gokalp A, Sosuncu E, Kiymaz N: Comparison of simultaneous shunting to delayed shunting in infants with myelomeningocele in terms of shunt infection rate. Turk Neurosurg 21(3):397-402, 2011
2. Attenello FJ, Tuchman A, Christian EA, Wen T, Chang KE, Nallapa S, Cen SY, Mack WJ, Krieger MD, McComb JG: Infection rate correlated with time to repair of open neural tube defects (myelomeningoceles): An institutional and national study. Childs Nerv Syst 32(9):1675-1681, 2016

3. Bhandari J, Thada PK: Neural Tube Disorders. In: StatPearls, 2020

4. Bolt J, Rawicki B, Donellan S: Urological management of spina bifida. Aust Fam Physician 30(2):21-24, 2001

5. Botto LD, Moore CA, Khoury MJ, Erickson JD: Neural-tube defects. N Engl J Med 341(20):1509-1519, 1999

6. Chakraborty A, Crimmins D, Hayward R, Thompson D: Toward reducing shunt placement rates in patients with myelomeningocele. J Neurosurg Pediatr 1(5):361-365, 2008

7. Charney EB, Weller SC, Sutton LN, Bruce DA, Schut LB: Management of the newborn with myelomeningocele: Time for a decision-making process. Pediatrics 75(1):58-64, 1985

8. Committee Opinion No. 720 Summary: Maternal-fetal surgery for myelomeningocele. Obstet Gynecol 130(3):672-673, 2017

9. Copp AJ, Adzick NS, Chitty LS, Fletcher JM, Holmbeck GN, Shaw GM: Spina bifida. Nat Rev Dis Primers 1:15007, 2015

10. Cruz NI, Ariyan S, Duncan CC, Cuono CB: Repair of lumbosacral myelomeningoceles with double Z-rhomboid flaps. Technical note. J Neurosurg 59(4):714-717, 1983

11. Ersahin Y, Yurtseven T: Delayed repair of large myelomeningoceles. Childs Nerv Syst 20(6):427-429, 2004

12. Eseoglu M, Eroglu A, Kemer S, Arslan M: Determination of the effect of diameter of the SAC on prognosis in 64 cases operated for meningomyelocele. Korean J Spine 14(1):7-10, 2017

13. Gurbuz MS, Yuksel MO: The Association between the timing of shunt placement and shunt infection in hydrocephalus associated with myelomeningocele. Turk Neurosurg 30(1):9498, 2020

14. Hamamy $\mathrm{H}$ : Epidemiological profile of neural tube defects in Arab countries. Middle East Journal of Medical Genetics 3(1): 1-10, 2014

15. Idowu OE, Apemiye RA: Outcome of myelomeningocoele repair in sub-Saharan Africa: the Nigerian experience. Acta Neurochir (Wien) 150(9):911-913, 2008

16. John W, Sharrard W, Zachary RB, Lorber J, Bruce AM: A controlled trial of immediate and delayed closure of spina bifida cystica. Arch Dis Child 38(197):18-22, 1963

17. Kankaya Y, Sungur N, Aslan OC, Ozer K, Ulusoy MG, Karatay M, Oruc M, Gursoy K, Karaaslan O, Kocer U: Alternative method for the reconstruction of meningomyelocele defects: $\mathrm{V}-\mathrm{Y}$ rotation and advancement flap. $\mathrm{J}$ Neurosurg Pediatr 15(5):467-474, 2015

18. Khoshnood B, Loane M, de Walle H, Arriola L, Addor MC, Barisic I, Beres J, Bianchi F, Dias C, Draper E, Garne E, Gatt M, Haeusler M, Klungsoyr K, Latos-Bielenska A, Lynch C, McDonnell B, Nelen V, Neville AJ, O’Mahony MT, QueisserLuft A, Rankin J, Rissmann A, Ritvanen A, Rounding C, Sipek A, Tucker D, Verellen-Dumoulin C, Wellesley D, Dolk H: Long term trends in prevalence of neural tube defects in Europe: Population based study. BMJ 351:h5949, 2015 
19. Lobo GJ, Nayak M: V-Y plasty or primary repair closure of myelomeningocele: Our experience. J Pediatr Neurosci 13(4):398-403, 2018

20. Machado HR, Santos de Oliveira R: Simultaneous repair of myelomeningocele and shunt insertion. Childs Nerv Syst 2:107-109, 2004

21. Mapstone TB, Rekate HL, Nulsen FE, Dixon MS Jr, Glaser N, Jaffe M: Relationship of CSF shunting and IQ in children with myelomeningocele: A retrospective analysis. Childs Brain 11(2):112-118, 1984

22. McCraw JB, Penix JO, Baker JW: Repair of major defects of the chest wall and spine with the latissimus dorsi myocutaneous flap. Plast Reconstr Surg 62(2):197-206, 1978

23. Mitchell LE, Adzick NS, Melchionne J, Pasquariello PS, Sutton LN, Whitehead AS: Spina bifida. Lancet 364(9448):1885-1895, 2004

24. Munro IR, Neu BR, Humphreys RP, Lauritzen CG: Limberg-latissimus dorsi myocutaneous flap for closure of myelomeningocele. Childs Brain 10(6):381-386, 1983

25. Mustardé JC: Reconstruction of the spinal canal in severe spina bifida. Plast Reconstr Surg 42(2):109-114, 1968

26. Nejat F, Baradaran N, Khashab ME: Large myelomeningocele repair. Indian J Plast Surg 44(1):87-90, 2011

27. Oktem IS, Menkü A, Ozdemir A: When should ventriculoperitoneal shunt placement be performed in cases with myelomeningocele and hydrocephalus? Turk Neurosurg 18(4):387-391, 2008

28. Pang D: Surgical complications of open spinal dysraphism. Neurosurg Clin N Am 6(2):243-257, 1995

29. Pinto FC, Matushita H, Furlan AL, Alho EJ, Goldenberg DC, Bunduki V, Krebs VL, Teixeira MJ: Surgical treatment of myelomeningocele carried out at 'time zero' immediately after birth. Pediatr Neurosurg 45(2):114-118, 2009
30. Ramasastry SS, Cohen M: Soft tissue closure and plastic surgical aspects of large open myelomeningoceles. Neurosurg Clin N Am 6(2):279-291, 1995

31. Rintoul NE, Sutton LN, Hubbard AM, Cohen B, Melchionni J, Pasquariello PS, Adzick NS: A new look at myelomeningoceles: functional level, vertebral level, shunting, and the implications for fetal intervention. Pediatrics 109(3):409-413, 2002

32. Sankhla S, Khan GM: Reducing CSF shunt placement in patients with spinal myelomeningocele. J Pediatr Neurosci 4(1):2-9, 2009

33. Scheflan M, Mehrhof Al Jr, Ward JD: Meningomyelocele closure with distally based latissimus dorsi flap. Plast Reconstr Surg73(6):956-959, 1984

34. Shaer CM, Chescheir N, Schulkin J: Myelomeningocele: A review of the epidemiology, genetics, risk factors for conception, prenatal diagnosis, and prognosis for affected individuals. Obstet Gynecol Surv 62(7):471-479, 2007

35. Tuli S, Drake J, Lamberti-Pasculli M: Long term outcome of hydrocephalus management in myelomeningocele. Childs Nerv Syst 19:286-291, 2003

36. Tuli S, Drake J, Lawless J, Wigg M, Lamberti Pasculli M: Risk factors for repeated cerebrospinal shunt failures in pediatric patients with hydrocephalus. J Neurosurg 92:31-38, 2000

37. Tuncbilek E, Boduroglu K, Alikasifoglu M: Neural tube defects in Turkey: Prevalence, distribution and risk factors. Turk $\mathrm{J}$ Pediatr 41(3):299-305, 1999

38. VanderKolk CA, Adson MH, Stevenson TR: The reverse latissimus dorsi muscle flap for closure of meningomyelocele. Plast Reconstr Surg 81(3):454-456, 1988

39. Wald NJ: Folic acid and the prevention of neural-tube defects. N Engl J Med 350(2):101-103, 2004 